\title{
Qualidade do Ensino Fundamental Qual é o critério dos indicadores?
}

\author{
Quality of Elementary Education
}

What is the criterion of indicators?

\section{Calidad de la Enseñanza Primaria}

¿Cuál es el criterio de los indicadores?

MÔNICA PICCIONE GOMES RIOS*

Pontifícia Universidade Católica de Campinas, Campinas- SP, Brasil.

MARIA TERESA CERON TREVISOL**

Universidade do Oeste de Santa Catarina, Joaçaba- SC, Brasil.

\begin{abstract}
RESUMO: $\mathrm{O}$ artigo analisa as ações desencadeadas por gestores de escolas municipais da mesorregião catarinense a partir dos resultados do Ideb. O artigo apresenta um recorte de dados da pesquisa "Indicadores de qualidade do ensino fundamental na mesorregião oeste de Santa Catarina: estratégias e ações na rede pública municipal de ensino" (Obeduc/Capes). A coleta dos dados deu-se por meio de questionários e de entrevistas. O Ideb foi propulsor de ações pelos gestores e essas estratégias implicaram para além do alcance de resultados, o que indica o compromisso com os processos de ensino e aprendizagem.

Palauras-chave: Políticas públicas de avaliação. Ideb. Processos de ensino e aprendizagem.
\end{abstract}

\footnotetext{
* Doutora e Mestra em Educação pela Pontifícia Universidade Católica de São Paulo. Atualmente é professora da Pontifícia Universidade Católica de Campinas do Programa de Pós-Graduação em Educação e do Curso de Pedagogia. Integra o Grupo de Avaliação, Políticas e Sistemas Educacionais do PPGE-PUC-Campinas (GRAPSE). E-mail: monica.rios@puc-campinas.edu.br.

** Possui mestrado em Educação pela Pontifícia Universidade Católica do Rio Grande do Sul e doutorado em Psicologia Escolar e do Desenvolvimento Humano pela Universidade de São Paulo. Atualmente é professora da Universidade do Oeste de Santa Catarina e atua como professora e pesquisadora no Programa de Pós-graduação em Educação desta instituição. E-mail: mariateresa.trevisol@unoesc.edu.br.
} 


\begin{abstract}
The article analyzes the actions triggered by managers of municipal schools of the Santa Catarina mesoregion from the results of Ideb (Index of Basic Education Development). The article presents a data cut of the research "Quality indicators of elementary education in the western mesoregion of Santa Catarina: strategies and actions in the municipal public school network" (Obeduc/ Capes). Data collection was done though questionnaires and interviews. Ideb was a thruster of actions by managers and these strategies imply beyond the reach of results, which indicates commitment to the teaching and learning processes.

Keywords: Public evaluation policies. Ideb. Teaching and learning processes.
\end{abstract}

RESUMEN: El artículo estudia las acciones desencadenadas por gestores de escuelas municipales de la mesorregión catarinense a partir de los resultados del Ideb. El artículo presenta un recorte de datos de la investigación "Indicadores de qualidade do ensino fundamental na mesorregião oeste de Santa Catarina: estratégias e ações na rede pública municipal de ensino" (Obeduc/Capes). La recolección de los datos se dio por medio de cuestionarios y entrevistas. El Ideb impulsó acciones de los gestores y esas estrategias alcanzaron más allá de los resultados, lo que indica el compromiso con los procesos de enseñanza y aprendizaje.

Palabras clave: Políticas públicas de evaluación. Ideb. Procesos de enseñanza y aprendizaje.

\title{
Introdução
}

$\mathrm{E}$ ste artigo constitui um recorte da pesquisa intitulada "Indicadores de qualidade do ensino fundamental na mesorregião oeste de Santa Catarina: estratégias e ações na rede pública municipal de ensino (2010-2014)”, vinculada ao Programa Observatório da Educação - (Obeduc) do Programa de Pós-Graduação em Educação da Unoesc (PPGE/Unoesc), que contou com o apoio financeiro da Coordenação de Aperfeiçoamento de Pessoal de Nível Superior (Capes), com o objetivo de identificar as estratégias e ações de 18 municípios e escolas da mesorregião, ao que se refere a uma educação de qualidade no ensino fundamental. Definiu-se um conjunto de procedimentos para a produção de material empírico e entre eles situa-se a recolha de dados, por meio de 
questionário, tendo como sujeitos os secretários municipais de educação e os gestores escolares; e por meio de entrevista, tendo como participantes os gestores escolares e os professores de $5^{0}$ e ${ }^{0}$ anos do ensino fundamental das disciplinas de Língua Portuguesa e Matemática. A aplicação dos questionários, seguida da realização das entrevistas, tendo como sujeitos os gestores escolares, deu-se em duas etapas. A primeira, cujos dados são analisados nesse artigo, considerou a edição 2009 da Prova Brasil, com a aplicação do questionário nos meses finais de 2011 e realização das entrevistas nos meses iniciais de 2012. Na segunda, considerando a edição 2011 da Prova Brasil, o questionário foi aplicado nos meses finais de 2012 e as entrevistas, nos meses iniciais de 2013.

As questões do questionário e do roteiro de entrevista versaram sobre quatro dimensões, a saber: I - infraestrutura escolar; II - gestão educacional; III - formação dos profissionais do magistério da educação básica; IV - práticas pedagógicas para o ensino e aprendizagem em Língua Portuguesa e Matemática.

O critério de seleção dos dezoito municípios que integraram a pesquisa considerou o corte populacional, a localização na mesorregião e, ao menos, 50\% de municípios considerados prioritários para receber auxílio técnico e/ou financeiro do Ministério de Educação (MEC). Em relação à escola considerou-se o menor Ideb registrado no ano de 2007 e que, preferencialmente, tivesse ensino fundamental completo.

\section{Objetivo e percurso metodológico}

Constitui objetivo desse artigo analisar as ações desencadeadas pelos gestores de escolas de 18 municípios da mesorregião catarinense, no período de 2011 a 2012, sobre educação de qualidade no ensino fundamental. As ações foram analisadas a partir das respostas dos gestores escolares às questões do questionário e das entrevistas que abarcaram as quatro dimensões algures citadas. Em uma via de mão dupla, objetivou-se, ainda, discutir a implicação do resultado do Ideb no desenvolvimento das estratégias de ação, e o impacto das ações no resultado do Ideb.

Para efeito deste recorte, considerou-se as respostas dos questionários e das entrevistas, tendo como participantes os gestores escolares, no período de 2011 a 2012. A opção pelo foco na primeira etapa da pesquisa justifica-se pela possibilidade de captar as ações desencadeadas pelos gestores das escolas pesquisadas isentas da possível sensibilização para esse fim que a pesquisa em si possa ter se ocupado de desenvolver, o que, potencialmente, poderia comprometer a espontaneidade no processo de geração de ações em prol da melhoria da qualidade.

O questionário foi disponibilizado on-line em um site específico da referida pesquisa, vinculada ao Obeduc, de modo que os participantes, após responderem, seguissem com o envio. 
O roteiro das entrevistas com os gestores escolares foi organizado por escola, a partir das respostas dos questionários. Houve, porém, uma questão comum que abarcou todos os gestores e que versou sobre a implicação do resultado do Ideb no desenvolvimento das estratégias de ação, e o impacto das ações no resultado do Ideb.

A abordagem metodológica na análise do quadro de ações e estratégias desenvolvidas pelas escolas dos respectivos municípios ancorou-se em pressupostos da pesquisa qualitativa, considerada a dimensão quantitativa como parte do processo analítico.

A análise prosseguiu a partir da referida organização e das dimensões elencadas. Inicialmente, foi feita a análise por município/escola e, posteriormente, realizou-se a análise geral, apresentada nesse artigo, incluindo os dados dos 18 municípios/escolas pesquisados.

Na apresentação das respostas dos sujeitos, adotou-se a letra $G$ para identificação de gestores escolares, acompanhada do índice numérico relativo a cada município/escola, a saber: 1 Calmon; 2 Caxambu do Sul; 3 Concórdia; 4 Dionísio Cerqueira; 5 Entre Rios; 6 Formosa do Sul; 7 Galvão; 8Ibiam; 9 Itapiranga; 10 Joaçaba; 11Lebon Régis; 12 Lindóia do Sul; 13 Palmitos; 14 Santa Terezinha do Progresso; 15 São Lourenço do Oeste; 16 São Miguel do Oeste; 17 Vargem Bonita; 18 Videira.

\section{Qualidade no ensino fundamental e avaliações em larga escala}

Nessa segunda década do século XXI, a qualidade do ensino fundamental, em nível nacional, tem sido expressa por meio do Índice de Desenvolvimento da Educação Básica (Ideb). Criado em 2007 pelo Instituto Nacional de Estudos e Pesquisas Educacionais (Inep/ MEC), o Ideb reúne informações do desempenho e do rendimento escolar. Ao que se refere ao ensino fundamental, o rendimento escolar considera os dados sobre aprovação, extraídos do censo escolar; e o desempenho encerra a nota da Prova Brasil. O cálculo do Ideb, cuja escala vai de zero a dez e cujo modelo de aferição é majoritariamente quantitativa, dá-se por meio do produto da Prova Brasil (0 a 10) e o rendimento escolar, sendo este baseado na taxa de aprovação (0 a 1).

De caráter diagnóstico e censitário, a Prova Brasil é realizada a cada dois anos ao final 5ㅜ e $9^{\circ}$ anos do ensino fundamental, sendo avaliadas as disciplinas de Língua Portuguesa e Matemática, tendo como propósito subsidiar os estados, municípios e Distrito Federal com informações sobre seus sistemas de ensino, com vistas a desencadear ações voltadas para minimizar as principais dificuldades identificadas nos processos de ensino e aprendizagem e direcionar suporte técnico e financeiro, em prol da melhoria da qualidade educacional. 
A Prova Brasil inscreve-se em uma lógica de avaliação focada no resultado de desempenho dos estudantes. Sobretudo na década de 1990 é que se intensifica a preocupação com o desempenho escolar dos estudantes da educação básica. Nessa década, com a assunção do Estado-avaliador, a avaliação constitui elemento central da gestão pública e parte fundante das políticas educacionais. Afirma Afonso que:

A presença do Estado-avaliador no nível de ensino não-superior expressa-se sobretudo pela promoção de um ethos competitivo que começa agora a ser mais explícito quando se notam, por exemplo, as pressões exercidas sobre as escolas nos níveis de [...] ensino fundamental e médio no Brasil através da avaliação externa [...] e através de um predomínio de uma racionalidade instrumental e mercantil que tende a sobrevalorizar indicadores e resultados acadêmicos quantificáveis e mensuráveis sem levar em consideração as especificidades do contexto e dos processos educativos (2001: 26).

A racionalidade instrumental implica controle permanente por meio da avaliação, que assume o objetivo de medir, classificar, certificar, tendo em vista a medida esperada, e, por vezes, converte-se em uma ação sentenciosa, traduzida por ações que versam entre a recompensa e a punição, dependendo dos resultados obtidos.

Considerando que avaliação e qualidade estão intrinsecamente relacionadas, é oportuno problematizar: qual o contributo das avaliações externas, em um modelo de racionalidade instrumental, para a construção de uma educação básica de qualidade?

A Prova Brasil, integrante do Ideb, é reconhecida por Bonamino e Sousa (2012) como sendo de segunda geração, em função da tendência das políticas de responsabilização que têm gerado a polarização das práticas pedagógicas e do currículo escolar para a obtenção de resultados.

A política de responsabilização identificada na segunda geração em que se encontra a Prova Brasil pode gerar avanços, identificados como tendências, e/ou retrocessos, identificados como tendenciosidades (PENNA FIRME, 1994). Ao que se refere à Prova Brasil e ao Ideb, pode-se considerar que a criação de um instrumento de aferição de qualidade da educação básica indica avanço, no que tange ao acompanhamento e monitoramento da realidade educacional brasileira; contudo, há o risco das práticas pedagógicas estarem polarizadas para os resultados da Prova Brasil e do Ideb, sem espaços nas unidades escolares para que tais resultados sejam problematizados e articulados aos processos de avaliação interna. Tal polarização tem implicações no currículo do ensino fundamental que pode estar a serviço da avaliação externa. Como assevera Gatti (2014:21), “currículos para a formação na educação básica são muito mais abrangentes e portadores de uma filosofia educacional dinâmica mais ampla, do que o que espelha uma matriz operacional de avaliação que, necessariamente, é restrita em seu escopo".

Outro aspecto a ser considerado refere-se ao Ideb, alçado a indicador de qualidade do ensino fundamental, não considerar os fatores intra e extraescolares que afetam os 
processos de ensino e aprendizagem, o que contribui para intensificar as desigualdades sociais e o ethos competitivo decorrente da divulgação dos resultados do Ideb. Nessa direção, Freitas salienta que:

O verdadeiro limite à universalização da melhoria da qualidade da escola é a própria ideologia meritocrática liberal. Caso a avaliação se coloque a serviço dela, então ficará limitada à medição do mérito e à ocultação da desigualdade social sob a forma de indicadores "neutros" como o Índice de Desenvolvimento da Educação Básica (IDEB) criado pelo MEC (2007: 971).

\section{Oliveira corrobora com essa advertência, ao considerar que:}

A origem social dos alunos, comumente identificada nos testes, mas relegada nas análises dos resultados obtidos, é a principal determinante da trajetória escolar. Estudos e pesquisas mostram que essas dimensões afetam sobremaneira os processos educativos e os resultados escolares e não podem ser desprezadas (2014:239).

Os resultados das avaliações externas, no caso da Prova Brasil podem contribuir para desencadear reflexões no âmbito da escola, sobretudo se articulados aos processos de avaliação institucional e de aprendizagem, e se considerados os condicionantes intra e extraescolares, o que implica a problematização dos usos que se faz desses resultados. No entanto, se as práticas pedagógicas e curriculares estiverem polarizadas para a elevação de resultados, e se o Ideb for considerado o indicador de qualidade do ensino fundamental e não um dos indicadores, cabe questionar a serviço de que e de quem estão a Prova Brasil e o Ideb. Dourado, Oliveira e Santos, salvaguardando a polissemia do conceito de qualidade, afirmam que:

a qualidade da educação envolve dimensões extra e intraescolares e, nessa ótica, deve-se considerar os diferentes atores, a dinâmica pedagógica, os processos de ensino-aprendizagem, os currículos, as expectativas de aprendizagem, bem como os diferentes fatores extraescolares que interferem direta ou indiretamente nos resultados educativos (2007:9).

Nessa perspectiva, cabe a problematização sobre o papel dos indicadores no contexto da escola: o que efetivamente indicam e o que movem a partir de sua divulgação? Estamos tratando de indicadores que colaboram para a construção do projeto de escola e de cidadão que desejamos? Ou as escolas se voltam para a lógica dos resultados, dos simulados e não avançam em processos de aprendizagem mais efetivos?

Na pesquisa realizada, base empírica desse artigo, considerando as escolas de 18 municípios da mesorregião catarinense, constatou-se a mobilização dos gestores escolares, em prol da elevação de resultados da Prova Brasil e do Ideb. No estado de Santa Catarina não há avaliação estadual, sendo predominante a política de responsabilização branda. As estratégias de ação desencadeadas, em acordo com os gestores escolares participantes da pesquisa, abarcaram as quatro dimensões elencadas: I - infraestrutura 
escolar; II - gestão educacional; III - formação dos profissionais do magistério da educação básica; IV - práticas pedagógicas para o ensino e aprendizagem em Língua Portuguesa e Matemática, consoante condicionantes intraescolares. Tais dimensões convergem com os planos apresentados por Dourado, Oliveira e Santos (2007), a saber: o plano do sistema; o plano de escola; o plano do professor; o plano do aluno - fatores intraescolares que afetam a qualidade da educação básica.

\section{Estratégias em prol da qualidade do ensino fundamental}

Conceder vez e voz aos sujeitos/profissionais que estão na escola (no caso deste artigo, os gestores escolares, que, por estarem nesse lugar, são desafiados a analisar, interpretar e a conduzir as questões problema da escola) constituiu diferencial para captar as ações em prol da qualidade do ensino fundamental.

Não somente os gestores, mas toda a escola precisa se tornar o centro da reflexão sobre si mesma, avaliando as ações pela qualidade da educação.

Em relação às ações e estratégias informadas no questionário pelos gestores escolares, a maior incidência deu-se em relação à dimensão I (infraestrutura escolar), com concentração nos eixos "recursos pedagógicos" e "condições físicas". As ações mais recorrentes, considerando-se acima de $20 \%$ das escolas pesquisadas, foram: - em relação aos recursos pedagógicos - aquisição de material didático-pedagógico, ampliação do acervo da biblioteca, aquisição de material pedagógico apostilado, e aquisição de equipamentos/eletrodomésticos; - em relação às condições físicas - aquisição de mobiliário escolar; reforma do prédio escolar ou dependências específicas, viabilização da internet; ampliação da estrutura física (salas de aula ou outras dependências) e instalação de laboratório de informática.

A saliência dessa dimensão converge com o plano do sistema, que encerra condições de oferta de ensino apresentado no estudo de Dourado, Oliveira e Santos (2007). Neste quesito, as instalações, o ambiente escolar, os equipamentos, entre outros, integram fatores intraescolares que incidem na qualidade educacional.

No que se refere à aquisição de recursos pedagógicos e material didático e às reformas no prédio escolar, as gestoras escolares G1 declararam que "tivemos mais espaço e facilitou para o bom desempenho das atividades pedagógicas. As crianças estão mais alegres, e participam mais das atividades, os professores estão gostando" (G1).

Na opinião do G8, a melhora na estrutura física da escola: "[...] contribuiu para os processos de ensino aprendizagem, pois os alunos tiveram mais espaço para brincar, ter atividade de educação física, realização de jogos e eventos como a nossa festa, sua construção é de grade importância. Com relação às salas de aula ficamos com mais espaço, permitindo a realização de salas ambiente e de oficinas como sala de música, informática". 
Os depoimentos dos gestores participantes da pesquisa evidenciam o que os autores supracitados apontam sobre o espaço físico apropriado e a quantidade e qualidade dos equipamentos disponibilizados para professores e alunos nos processos de ensino e aprendizagem.

Sobre os equipamentos e as instalações de informática, G1, G3 e G5 salientaram que "sempre enriquece mais, a informática vem para contribuir e os alunos gostam. [...] Os demais, como jogos e o livro didático contribuem muito, e ajudam o professor, nas suas aulas, os jogos de montar tem nos auxiliado bastante. Os alunos demonstram mais interesses em participar das atividades [...]". (G1). "Além daquele material didático necessário de sala de aula, biblioteca, o laboratório de informática veio a ajudar o nosso aluno, por que ele sai da prática de sala de aula e vai procurar a realidade do dia a dia no laboratório de informática" (G3). "Os alunos melhoraram, eles se dedicam em querer aprender, tudo que tem no computador eles querem, eles perguntam" (G5).

Nesse aspecto, vale ressaltar que há o reconhecimento de que as tecnologias de informação e comunicação (TIC) contribuem para o desenvolvimento das aulas, o que potencialmente pode favorecer as aprendizagens, sendo necessário que se intensifique o uso pedagógico das TIC.

G6 aponta a articulação escola/família, ressaltando a importância da melhoria da infraestrutura física escolar para favorecer a participação da família e, por consequência, dos processos de ensino e aprendizagem. "[...] procuramos fazer mais, colocando a família na escola, melhorando a estrutura física da escola e isso ajudou no ensino e aprendizagem dos alunos. A escola articula melhor a participação da família na escola. A melhora na infraestrutura melhora a aprendizagem dos alunos" (G6).

O reconhecimento de que a infraestrutura física escolar favorece a integração escola/ família demonstra a articulação entre as dimensões que se referem à qualidade da educação e reforça a importância da gestão escolar nesse processo de construção.

A segunda maior concentração de ações, conforme declaram os gestores no questionário, deu-se na dimensão II (gestão escolar) nos eixos "planejamento", "recursos humanos", "recursos financeiros" e "parcerias", nessa ordem de incidência de ações e estratégias, a saber: - planejamento - reformulação do projeto político pedagógico da escola (PPP), realização da avaliação institucional, planejamento coletivo, e realização de planejamento de atividades pedagógicas - recursos humanos - acompanhamento psicológico na escola, e recursos financeiros - captação de recursos do Programa Dinheiro Direta na Escola (PDDE); - parcerias - busca de apoio de instituições de educação superior para a realização e palestras.

Na entrevista, as falas de G3 e G16 confirmam a necessidade de se estender a participação no processo de elaboração e revisão do PPP a toda comunidade escolar.

"Todo final de ano a gente senta, reavalia o que deu certo, o que não deu certo e o que a gente pode alterar no nosso PPP. A construção do PPP acontece no grande grupo, não é o gestor, não é o orientador, não é o secretário que faz, enfim, é o grupo de professores que faz, não só efetivos, 
e sim, professores que integram o quadro de professores" (G3). "[... o o PPP, a cada ano, a gente rezê. Ele está sendo reconstruído agora, novamente. A gente sempre senta num grupo juntamente com os professores, com alguns pais quando for preciso" (G16).

Essas falas expressam o compromisso dos profissionais das escolas com o PPP, em um esforço de construção coletiva e, mais uma vez, sublinham a necessidade de atenção da gestão para a organização do trabalho escolar. No entanto, é necessário avançar para que haja evidências de pais e funcionários envolvidos no processo de construção do PPP, de modo a expressar a ampliação de participação de toda a comunidade escolar por meio de uma gestão democrática.

Em relação aos recursos humanos, G5 destacou a contratação de especialistas como contributo para os processos de ensino e aprendizagem. "Trabalhando juntas, fonoaudióloga e psicóloga, estamos vendo que a aprendizagem está melhorando a cada dia na escola [...] Temos assistente social também, mas infelizmente ela não trabalha aqui na escola. Nós batalhamos juntos com a fonoaudióloga, a psicóloga e a nutricionista" (G5).

Na fala expressa por G5 evidencia-se a importância de uma equipe multidisciplinar que atue de forma integrada, em prol das aprendizagens dos alunos, que constitui o foco principal da escola.

Sobre o financiamento, G18 afirmou que a biblioteca foi atualizada com os recursos do Programa Dinheiro Direto na Escola (PDDE). "A gente acredita que sim, mas em relação ao acervo da biblioteca, muito pouco veio do governo federal, muitas coisas foram compradas com o dinheiro direto na escola. E assim, os recursos tecnológicos nesse período, a gente ganhou da secretaria da educação o laboratório e o multimídia foi comprado" (G18).

Fica expressa, na fala de G18, a importância do movimento protagonizado, sobretudo, pelo gestor escolar para que a escola concretize ações que dependem de recursos financeiros, o que implica um dos maiores desafios a ser enfrentados por quem está à frente da gestão.

Nas parcerias, G3 demonstrou que elas foram motivadas pelo baixo índice do Ideb. Na fala da gestora fica expressa a preocupação com o processo de formação dos professores. "Em 2009 (...) o nosso índice do Ideb foi um tanto quanto baixo (...) nós procuramos parcerias com a secretaria de Educação, com os próprios núcleos da Universidade do Contestado (...); a própria secretaria é parceira na formação continuada, dando esse suporte ao professor" (G3).

Na sequência de concentração de ações destaca-se a dimensão IV (práticas pedagógicas para o ensino e aprendizagem em Matemática e Língua Portuguesa), no eixo "organização didático-pedagógica", seguido do eixo "organização escolar", tendo sido as ações mais recorrentes: - organização didático-pedagógica - realização de aulas de reforço escolar para alunos com dificuldades de aprendizagem; - organização escolar implementação de medidas de combate à evasão e/ou repetência escolar, e implantação do ensino fundamental de nove anos. 
A importância do reforço escolar, destacado pelas gestoras, pode ser evidenciada nas falas que seguem de G1 e G11: "O reforço tem nos auxiliado nas dificuldades dos alunos, eles conseguem desenvolver o raciocínio lógico com mais facilidade que antes não acontecia" (G1). "Tem sido muito importante para a melhoria das aprendizagens de Português e Matemática. Julgo como muito importante e que tem dado um bom resultado" (G11).

Ao se referir ao reforço escolar, G8 destaca a contribuição dos materiais didáticos adquiridos. "O material didático-pedagógico vem sendo adquirido e usado conforme o planejamento do professor. Esse material é utilizado tanto em sala como para as oficinas de reforço" (G8). Estas falas evidenciam que o reforço escolar foi considerado significativo para os processos de ensino e aprendizagem no desenvolvimento de atividades e uso de materiais diferenciados.

Destaca-se a fala de G15, que aponta o reforço como uma preparação para a Prova Brasil, o que enseja uma distorção do currículo, ainda que seja reconhecido, pela gestora, como um contributo para a aprendizagem. "Os projetos como reforço da Prova Brasil para os alunos do $7^{0}$ e 8o ano contribuem para a aprendizagem Matemática. O trabalho é mais individual. Os projetos facilitam a interação e aprendizagem entre os pares" (G15).

Em relação às medidas para combater à repetência, G3 destaca o reforço oferecido no contraturno. "A gente tem aquele aluno meio fraco em sala, ele vem em contraturno para sanar aquela dificuldade (...) é um recurso a mais em prol do nosso aluno" (G3).

Sobre o combate à evasão, a fala de G2 ilustra algumas iniciativas dos gestores pesquisados, o que implica "visitas nas casas para diminuir a evasão, colocar a responsabilidade para os pais, mais comprometimento" (G2).

Ao considerar que qualidade da educação implica acesso, permanência e sucesso escolar, as ações das escolas para minimizar a evasão refletem preocupação com a democratização da educação,

[...] a democratização da educação não se limita ao acesso à instituição educativa $\mathrm{O}$ acesso é, certamente, a porta inicial para a democratização, mas torna-se necessário, também, garantir que todos os que ingressam na escola tenham condições de nela permanecer, com sucesso Assim, a democratização da educação faz-se com acesso e permanência de todos no processo educativo, dentro do qual o sucesso escolar é reflexo da qualidade (BRASIL, 2009: 45).

A Dimensão III (formação dos profissionais do magistério da educação básica) foi a que apresentou menor índice de concentração de ações, no eixo da "formação continuada", cuja ação recorrente foi a realização de cursos de aperfeiçoamento sobre temas específicos. Curiosamente, a formação de professores, tanto inicial como continuada, tem sido apontada pela literatura como fundamental para a melhoria da qualidade da educação, o que suscita indagação sobre ser a dimensão com menos concentração de ações.

Chama a atenção, ainda, que alguns professores do ensino fundamental nas escolas pesquisadas tenham declarado que o processo de formação continuada tende a ser 
verticalizado, com a seleção de temas que não vão ao encontro dos seus anseios frente aos desafios do cotidiano escolar. Isso remete à necessidade de se repensar as políticas dos municípios de formação continuada, tendo em vista que, conforme aponta Nóvoa:

A formação continuada deve estar articulada com desempenho profissional dos professores, tomando as escolas como lugares de referência. Trata-se de um objetivo que só adquire credibilidade se os programas de formação se estruturarem em torno de problemas e de projetos de ação e não em torno de conteúdos acadêmicos (1991:30).

Ainda que essa pesquisa não tenha se debruçado sobre os impactos da formação docente no desempenho dos alunos, há gestores que reconheceram o potencial da formação oferecida pelas unidades escolares e pelos municípios pesquisados, o que implica potencial para agregar valor a ser refletido na prática pedagógica.

G3 apontou a sistemática de formação continuada, considerando importante diferencial para os professores. "É uma proposta enquanto SEMED, Secretaria Municipal de Educação, que nos proporciona a formação continuada na escola. [...] é importantíssima a forma com que a SEMED trabalha, a forma com que proporciona essa formação continuada para a escola e para os professores" (G3).

Segundo G4, embora os professores da escola possuam titulação, a formação continuada contribui para o processo formativo. "Hoje a escola já não conta com um professor que não tenha uma formação. Mas, os cursos de capacitação vêm porque muitas coisas na faculdade você não consegue disseminar, você não consegue absorver tudo o que você precisa. Entãoé dentro desses cursos de capacitação que a gente procura ajudá-los" (G4).

As considerações a respeito da formação de professores responsabilizadas, por vezes, como a responsável pelo desempenho dos alunos, nos remetem à Gatti ao afirmar que há múltiplos fatores que incidem no desempenho das redes de ensino, tais como:

[...] as políticas educacionais postas em ação, o financiamento da educação básica, aspectos das culturas nacional, regionais e locais, hábitos estruturados, a naturalização em nossa sociedade da situação crítica das aprendizagens efetivas de amplas camadas populares, as formas de estrutura e gestão das escolas, formação dos gestores, as condições sociais e de escolarização de pais e mães de alunos das camadas populacionais menos favorecidas (os "sem voz") e, também, a condição do professorado: sua formação inicial e continuada, os planos de carreira e salário dos docentes da educação básica, as condições de trabalho nas escolas (2010: 1359).

Essa assertiva reitera a perspectiva de que a construção de uma educação de qualidade abrange condicionantes intra e extraescolares, não podendo ser reduzida ao desempenho dos alunos e que a responsabilidade sobre esses resultados, considerando o que encerra o Ideb (desempenho e fluxo escolar), pode ser atribuída tão somente aos gestores escolares e professores das redes de ensino. 
Paralelamente à preocupação das escolas com a obtenção do Ideb deve estar a com a construção do ser humano/aluno que frequenta a escola e busca nela o alargamento de suas condições de desenvolvimento e de aprendizagem.

\section{Impacto das estratégias de ação no Ideb}

Todos os gestores participantes da pesquisa consideram que as estratégias de ação provocaram mudanças e tiveram impacto no Ideb, ainda que possam ter sido movidas ou não por ele. Essa percepção dos gestores pesquisados teve como base o Ideb relacionado à edição 2007 da Prova Brasil, lançado em 2008, comparado ao Ideb, lançado em 2010, relativo à edição 2009 da Prova Brasil. Ficou explícito que houve mobilização das escolas na tentativa de diagnosticar as dificuldades, a fim de superá-las para elevar o índice do Ideb, ainda que esse propósito não tenha sido exclusivo, considerando a declaração dos gestores escolares que expressaram o compromisso com os processos de ensino aprendizagem, para além de resultados. "Acredito que foram importantes, sim, mas não só para o Ideb, mas todo o processo pedagógico" (G1). G2 foi imperativo ao responder que "Sim, para melhor. Os professores trabalham com os conteúdos específicos da Lingua Portuguesa e da Matemática. São realizados, também, simulados para preparar os alunos".

Ressalte-se que a Prova Brasil, em função do Ideb, provocou ações que implicam a preparação dos alunos, o que revela polarização de práticas pedagógicas, tendo o alcance dos índices como fim, convidando-nos a refletir sobre a necessidade de ressignificação dos indicadores pelos gestores escolares. Para G3, "o índice de 2009 do nosso Ideb melhorou e muito, graças ao quê? Ao vestir a camisa pelos professores, essa conversa, essa integração comunidade escola, comunidade escola e a parceria com estas entidades e a Secretaria de Educação". G5 comentou que "a melhora no resultado da Prova Brasil se deve ao esforço dos professores, à qualidade, os cursos que foram fazendo [...]. Depois trabalhando bastante a família, porque a gente fez várias reuniões. G6 observa que "procuramos fazer mais, colocando a família na escola, melhorando a estrutura física da escola e isso ajudou no ensino e aprendizagem dos alunos. A escola articula melhor a participação da família na escola. A melhora na infraestrutura melhora a aprendizagem dos alunos".

As falas de G3, G5 e G6 demonstram o esforço coletivo e a integração família/escola/ comunidade que incidiram na melhoria do Ideb. Destaca-se que, apesar da dimensão III, relativa à formação ter apresentado a menor recorrência no questionário, considerando os municípios pesquisados, G5 apontou a formação continuada dos professores como um diferencial para a efetivação da melhoria do Ideb.

Nas falas que seguem, sobre o impacto das ações na melhoria do Ideb, de G8, G9 demonstram uma atenção com o processo de aprendizagem para além da Prova Brasil e do referido índice. Nas suas falas fica evidente que a elevação do Ideb é consequência 
do aprendizado do aluno que se dá no cotidiano escolar. "Não só por causa da prova, a participação dos professores é voltada para aprendizagem no desenvolver de seu planejamento sendo que essa prova é importante, mas não a mais importante. Estão sempre planejando, sempre buscando o melhor para nossos alunos, tanto que nossa qualidade é muito boa" (G8). "Todo ano tem o curso de oratória que ajuda bastante. Mas eu penso que ainda podia ter sido mais, até porque não só visando ao Ideb, visa assim o aluno, o Ideb vai ser resultado disso" (G9).

Mais uma vez, o esforço coletivo vem à tona, ao se discutir melhorias no processo educativo. Ainda que haja reservas acerca de erigir o Ideb como indicador da qualidade educacional, a vigência do índice, do processo a ele associado parece também ser fator impulsionador do diálogo e do planejamento coletivo na escola pesquisada, com potencial para incidir na melhoria da qualidade do ensino.

G11 declara o reconhecimento da função social da escola e reitera a importância do trabalho coletivo. "Eu vejo que sim, mas não foi só pensando o Ideb. As ações voltadas à melhoria do bairro tiveram maior preocupação, tanto que os projetos planejados surpreenderam a nós mesmos, não imaginávamos que a comunidade iria se interessar tanto e participar. E a união do grupo foi fundamental, os professores trabalharam unidos" (G11).

A despeito do alerta tecido por Schneider e Nardi (2018:56) sobre o Ideb constituir o "tradutor oficial da qualidade nas e das escolas de educação básica brasileiras", as declarações dos gestores sobre os impactos das ações no Ideb evidenciam que, embora haja reconhecimento da repercussão, o índice não é seu único propulsor, ainda que algumas escolas estejam mais polarizadas pelo resultado. No conjunto, percebe-se que os gestores escolares tendem a associar as ações e estratégias à melhoria dos processos de ensino e aprendizagem e à melhoria do índice oficial como caminho para a construção de uma educação de qualidade.

\section{Considerações finais}

A concessão de voz aos gestores escolares no que se refere à educação de qualidade do ensino fundamental, entre os anos de 2011 e 2012, e a implicação do Ideb nesse processo evidenciaram que os resultados desse índice tem influência nas ações das unidades escolares, porém, há um compromisso dos gestores das 18 escolas pesquisadas com as estratégias de ação que contribuam para os processos de ensino e aprendizagem como elementos orientadores de ações. Essa constatação advém dos depoimentos dos gestores escolares quando apontam, também, ações para além dos resultados divulgados do Ideb e/ou das metas a serem atingidas pela escola.

Entre as ações desencadeadas pelos gestores escolares das escolas pesquisadas sobressaíram as relativas à infraestrutura escolar e à gestão escolar, e, em um segundo plano, as ações relativas às práticas pedagógicas e à formação continuada de professores. 
No conjunto de ações desencadeadas pelos gestores escolares, ainda que não seja possível precisar quais tenham maior ou menor influência no desempenho dos alunos, é fato que abarcam as quatro dimensões atreladas à qualidade da educação básica.

Desse conjunto, constatou-se que há gestores que formularam ações para incidir nas práticas escolares com vistas ao alcance das metas do Ideb traçadas para a escola. Contudo, ainda considerando o conjunto das escolas pesquisadas, para além das intenções, ganhos para os processos de ensino e aprendizagem podem ser destacados: articulação família/escola; planejamento coletivo; parcerias com universidades; problematização do cotidiano escolar, entre outros. Tais ações em prol da melhoria do ensino fundamental têm como foco os processos de ensino e aprendizagem, com vistas ao sucesso escolar, o que expressa a concepção de qualidade educacional dos participantes da pesquisa.

Permanece, porém, a indagação sobre como avançar para que os resultados da avaliação e dos indicadores possam contribuir para identificar ganhos e dificuldades e para desencadear ações que constituam contributo para a superação das dificuldades, a partir da problematização dos resultados articulada às atividades do cotidiano no contexto de cada unidade escolar.

Recebido: 01/07/2018 e Aprovado: 01/12/2018

\section{Referências}

AFONSO, Almerindo Janela. Reforma do estado e políticas educacionais: entre a crise e do Estadonação e a emergência da regulação supranacional. Educação e Sociedade, Campinas, CEDES, n. 75, p.15-32, ago. 2001.

BONAMINO, Alícia.; SOUSA, Sandra Zákia. Três gerações de avaliação da educação básica no Brasil: interfaces com o currículo da/na escola. Educação e Pesquisa, São Paulo, USP, v. 38, n. 2, p. 373-388, abr./jun. 2012.

BRASIL. Conferência Nacional de Educação 2010. Documento-referência. Brasília, DF, 2009.

DOURADO, Luiz Fernandes (coord.); OLIVEIRA, João Ferreira de; SANTOS, Catarina de Almeida. A Qualidade da Educação: conceitos e definições. Brasilia, 2007. pp. 6-32.

FREITAS, Luiz Carlos de. Eliminação adiada: o ocaso das classes populares no interior da escola e a ocultação da (má) qualidade do ensino. Educação e Sociedade, Campinas, CEDES, v. 28, n. 100, p. 965-987, 2007.

GATTI, Bernadete A. Avaliação: contexto, história e perspectivas. Olh@res, Guarulhos, UNIFEP, v. 2, n. 1, p. 08-26. Maio, 2014.

GATTI, Bernadete A. Formação de professores no Brasil: características e problemas. Educação e Sociedade, Campinas, CEDES, v. 31, n. 113, p. 1355-1379, out.- dez. 2010. 
NÓVOA, António. O passado e o presente dos professores: profissão professor. Porto: Porto Editora, 1991.

OLIVEIRA, Dalila Andrade. A política educacional brasileira: entre a eficiência e a inclusão democrática. Educação e Filosofia, Uberlândia, UFU, v. 28, n. 1Esp., 2014.

PENNA FIRME, Thereza. Avaliação: tendências e tendenciosidades. Revista Ensaio, Rio de Janeiro, UFF, v.1, n.2, p. 5-12, jan/mar 1994.

SCHNEIDER, Marilda Pasqual; NARDI, Elton Luiz. O IDEB e as prioridades no planejamento educacional: ações para qual qualidade? Revista de Educação PUC-Campinas, Campinas, PUCCampinas, v.23, n.1, p.54-64, 2018. 